\title{
FAUNA IXODÍDEA DE ANIMAIS SILVESTRES DO ESTADO DO PARANÁ, BRASIL - DADOS PRELIMINARES
}

(Ixodid fauna of wild animals from Paraná State, Brazil - preliminary data)

${ }^{1}$ Jessica Damiana Marinho Valente, ${ }^{1}$ André Saldanha, ${ }^{1}$ Rafaella Martini, ${ }^{1}$ Rogério Ribas Lange, ${ }^{2}$ Thiago
Fernandes Martins, ${ }^{1}$ Thállitha S. W. J. Vieira, ${ }^{1}$ Rafael F. C. Vieira

1 Universidade Federal do Paraná, Curitiba, Paraná, Brasil. ²Faculdade de Medicina Veterinária, Universidade de São Paulo, São Paulo, Brasil.

*Correspondência: rvieira@ufpr.br

RESUMO: Os carrapatos são conhecidos por parasitar uma variedade de hospedeiros domésticos e silvestres, incluindo mamíferos, aves, répteis e anfíbios. Além disso, muitos animais silvestres participam do ciclo epidemiológico de doenças transmitidas por carrapatos. Nesse sentido, o objetivo desse estudo foi identificar as espécies de carrapatos parasitando animais silvestres provenientes de municípios do estado do Paraná (Curitiba e região metropolitana, Foz do Iguaçu e Londrina) e atendidos no Hospital Veterinário, Universidade Federal do Paraná, Curitiba, Brasil. Os carrapatos foram coletados de 28 animais silvestres: uma (4\%) anta (Tapirus terrestres), um (4\%) cervídeo (Mazama sp.), um (4\%) javali (Sus scrofa), dois (7\%) bugios (Alouatta guariba), duas (7\%) capivaras (Hydrochoerus hydrochaeris), 9 (32\%) ouriços-cacheiros (Sphiggurus villosus), quatro (14\%) tamanduás-mirins (Tamandua tetradactyla), seis (21\%) gambás (Didelphis spp.), um (4\%) gato-mourisco (Herpailurus yagouaroundi) e um (4\%) teiú (Tupinambis sp.). Ao todo, foram coletados 115 carrapatos, sendo 65 (56\%) machos (M), 33 (29\%) fêmeas (F) e $17(15 \%)$ ninfas (N): Amblyomma aureolatum (1M, 3F, 2N) em dois bugios, um gambá e um gato-mourisco; Amblyomma calcaratum (8M, 2F) em 4 tamanduás-mirins; Amblyomma dubitatum (6M, 1F, 7N) em duas capivaras e um gambá; Amblyomma fuscum (3F) em um teiú; Amblyomma longirostre (28M, 8F, 4N) e Amblyomma parkeri (4M, 3F, 3N) em nove ouriços-cacheiros; Amblyomma ovale (1F) em um javali; Amblyomma sculptum (6M, 7F) em uma anta e um javali; Haemaphysalis juxtakochi (1N) em um cervídeo e Ixodes loricatus (12M, 5F) em cinco gambás. Estudos são necessários para melhor avaliar o papel dessas espécies na epidemiologia das doenças transmitidas por carrapatos.

Palavras-chave: carrapatos; animais selvagens; Amblyomma spp.; Haemaphysalis spp.; Ixodes spp. 